\title{
Age-related deficits in synaptic plasticity rescued by activating PKA or PKC in sensory neurons of Aplysia californica
}

\author{
Andrew T. Kempsell and Lynne A. Fieber* \\ Department of Marine Biology and Ecology, Rosenstiel School of Marine and Atmospheric Science, University of Miami, \\ Miami, FL, USA
}

Brain aging is associated with declines in synaptic function that contribute to memory loss, including reduced postsynaptic response to neurotransmitters and decreased neuronal excitability. To understand how aging affects memory in a simple neural circuit, we studied neuronal proxies of memory for sensitization in mature vs. advanced age Aplysia californica (Aplysia). L-Glutamate- (L-Glu-) evoked excitatory currents were facilitated by the neuromodulator serotonin $(5-\mathrm{HT})$ in sensory neurons $(\mathrm{SN})$ isolated from mature but not aged animals. Activation of protein kinase $A(P K A)$ and protein kinase $C(P K C)$ signaling rescued facilitation of L-Glu currents in aged SN. Similarly, PKA and PKC activators restored increased excitability in aged tail SN. These results suggest that altered synaptic plasticity during aging involves defects in second messenger systems.

Keywords: short term memory, long term potentiation, pleural ganglion, pedal ganglion, marine invertebrate

\section{Introduction}

Aging affects several cellular properties of neurons, causing a progressive decline in neuronal excitability and synaptic function, and culminates in sensory and motor deficits and memory loss (Kumar and Foster, 2007; Kumar et al., 2012). Decreased synaptic strength during aging is the result of declines in postsynaptic responsiveness including decreases in level of expression of ionotrophic glutamate receptors (iGluR; Magnusson et al., 2002). We previously demonstrated that L-glutamate (L-Glu) activated excitatory currents in isolated tail sensory neurons (SN) of the marine snail Aplysia californica (Aplysia; Carlson and Fieber, 2011; Carlson et al., 2012), but that L-Glu-induced current amplitude was decreased significantly in old tail SN (Fieber et al., 2010; Kempsell and Fieber, 2014), suggesting that losses in SN excitability are a hallmark of aging.

Direct stimulation of the tail initiates the tail withdrawal reflex (TWR). TWR involves identified SN in the pleural ganglia and motoneurons (MN) in the pedal ganglia (Walters et al., 1983a, 2004). Distinct forms of nonassociative learning can be evoked in TWR. Sensitization in TWR is an increase in reflexive response following an aversive shock to part of the body.

Received: 19 May 2015

Accepted: 19 August 2015 Published: 03 September 2015

Citation:

Kempsell AT and Fieber LA (2015)

Age-related deficits in synaptic plasticity rescued by activating PKA or PKC in sensory neurons of Aplysia californica.

Front. Aging Neurosci. 7:173. doi: 10.3389/fnagi.2015.00173

\footnotetext{
Abbreviations: AMPAR, alpha-amino-3-hydroxy-5-methylisoxazole-4-propionic acid receptors; AP, action potential; ASW, artificial seawater; cAMP, cyclic monophosphate; dbcAMP, dibutyryl adenosine $3^{\prime}, 5^{\prime}$-cyclic monophosphate; EPSP, excitatory postsynaptic potential; iGluR, ionotrophic glutamate receptors; L-Glu, L-glutamate; LTD, long-term depression; LTP, long-term potentiation; NMDAR, N-methyl-D-aspartate receptors; PKA, protein kinase A; PKC, protein kinase C; PMA, phorbol 12-myristate 13-acetate; MN, motoneuron; PVC, pleural ventral caudal; SN, sensory neuron; TWR, tail-elicited tail withdrawal reflex; 5-HT, serotonin.
} 
Short- and long-term forms of sensitization can be induced depending on the quantity and pattern of training (Walters et al., 1983b; Stopfer and Carew, 1996; Stopfer et al., 1996; Sutton et al., 2002; Glanzman, 2009). These changes in behavior are reflected in concurrent changes in the efficacy between tail SN and MN synapses.

The molecular pathways involved in these forms of learning are well-studied (Kandel, 2001; Glanzman, 2008). For example, the neuromodulator serotonin $(5-\mathrm{HT})$ is released at the SNMN synapse during sensitization, resulting in increased tail SN excitability and an increase in tail SN-MN transmission (Brunelli et al., 1976; Walters et al., 1983b; Glanzman et al., 1989; Mackey et al., 1989; Mercer et al., 1991; Levenson et al., 1999; Marinesco and Carew, 2002; Philips et al., 2011). 5-HT released during synaptic facilitation activates protein kinase A (PKA)- and protein kinase C (PKC)induced signaling in both the $\mathrm{SN}$ and $\mathrm{MN}$ (Glanzman, 2008; Villareal et al., 2009). Activation of these second messenger cascades results in dynamic processes involved in the formation and maintenance of memory. For example, in short-term facilitation ( $\leq 30 \mathrm{~min})$, a brief pulse of 5HT activates adenylyl cyclase in presynaptic neurons, causing an increase in cyclic adenosine monophosphate (cAMP), activation of PKA, and closing of $\mathrm{K}^{+}$channels. Closure of $\mathrm{K}^{+}$channels increases action potential (AP) duration and thus raises presynaptic cytosolic $\mathrm{Ca}^{2+}$, causing increased release of neurotransmitter into the synaptic cleft and temporary strengthening of the synapse. Longer exposures to 5-HT cause the prolonged activation of presynaptic PKA and induce longterm facilitation $(\geq 24 \mathrm{~h})$. Long-term facilitation requires both transcription and translation. Prolonged PKA activity results in the phosphorylation of transcription factors such as CREB-1, stimulating RNA and protein synthesis (Van der Zee et al., 1997, 2004; Oh et al., 2009).

Our prior studies describing aging in Aplysia TWR suggested that changes in tail SN excitability, whether in isolated SN or in $\mathrm{SN}$ of reduced ganglia-tail preparations, are reliable and electrophysiologically tractable features of the aging of TWR. In this study we investigated proxies for synaptic plasticity in tail SN during aging, including 5-HT-induced changes in excitability. We found that aging impairs the normal 5-HTmediated response of enhancing SN excitability. Activating PKA and PKC signaling in aged SN partially restored 5-HT-induced excitability.

\section{Materials and Methods}

Full or half sibling cohorts of Aplysia from the University of Miami National Resource for Aplysia were raised from egg masses of wild-caught animals. They were reared on an ad-libitum diet consisting of Gracilaria ferox and Agardhiella subulata as described previously (Gerdes and Fieber, 2006). Sexual maturity for a cohort of animals was designated as the day the first egg mass was laid.

Electrophysiological experiments were executed at maturity and when the animals reached stage aged II, as described previously (Kempsell and Fieber, 2014). Mature animals were age
$7-8$ months and sexually reproductive for $<1$ month at the time of experiments. Aged II animals were age 12-13 months, and had reduced performance in the righting reflex, TWR, and biting response compared to mature and aged I siblings (Kempsell and Fieber, 2014).

\section{Whole-Cell Voltage Clamp of Isolated, Cultured SN}

Pleural ventral caudal (PVC) SN were isolated from pleural ganglia, dissociated onto $35 \times 10 \mathrm{~mm}$ polystyrene culture plates coated with poly-D-lysine, and the primary cultures stored at $17^{\circ} \mathrm{C}$ in a humidified atmosphere as described (Fieber, 2000; Fieber et al., 2013). Whole-cell voltage clamp recordings were made $24-48 \mathrm{~h}$ after plating using $1.5 \mathrm{~mm}$ outer diameter borosilicate glass microelectrodes and an Axopatch 200B patch clamp amplifier connected to a PC equipped with a Digidata 1440 A/D converter and pClamp10 software (Molecular Devices, Sunnyvale, CA, USA). Experiments were performed in continuously flowing artificial seawater (ASW) while L-Glu was applied at $1 \mathrm{mM}$ in ASW for $100 \mathrm{~ms}$ via a micropipette attached to a picospritzer positioned $\sim 30 \mu \mathrm{m}$ from the cell body at an angle of $\sim 45^{\circ}$ with the perfusion outflow pipette. $\mathrm{SN}$ responses to L-Glu were recorded from a holding potential of $-70 \mathrm{mV}$ every 60 s. Five pre-treatment L-Glu-evoked currents were recorded and the baseline response was calculated from their average. 5HT $(20 \mu \mathrm{M})$, dibutyryl adenosine $3^{\prime}, 5^{\prime}$-cyclic monophosphate (dbcAMP; $20 \mu \mathrm{M}$ ), or phorbol 12-myristate 13-acetate (PMA; $50 \mathrm{nM}$ ) in ASW was then perfused into the recording chamber for 10 min while L-Glu-evoked currents were recorded. After 10 min treatment, washout of treatment began, and L-Glu-evoked currents continued to be recorded every $60 \mathrm{~s}$ for an additional 10 min (10 min washout). PVC SN from the same cohort of animals were studied at maturity and aged II.

\section{Intracellular Recording of Tail SN in Semi-Intact Tail Preparation}

Electrophysiological experiments in semi-intact preparations involved tail SN responses to injected current before and after application of PMA or dbcAMP from the same cohort of animals at maturity and aged II. Animals were anesthetized by injection of isotonic $\mathrm{MgCl}_{2}(\sim 50 \%$ animal weight by volume) into the body cavity. A ganglia-tail preparation was made, consisting of either the left or right pleural-pedal hemiganglia that remained connected to the tail by nerve p9 (Kempsell and Fieber, 2015); all other connectives were severed. The gangliatail preparation was pinned tightly to a Sylgarded dish. Use of a semi-intact tail preparation allowed for verification of tail SN response to tail touch. The other ganglia were removed from the remaining animal tissue to euthanize it, and unneeded ganglia and tissue were discarded. Ganglia were surgically desheathed and maintained in ASW via a gravity-fed perfusion pipette located $\sim 5 \mathrm{~mm}$ from the ganglia. Tail $\mathrm{SN}$ had resting potentials of $-40-55 \mathrm{mV}$ and were not spontaneously active, but when receptive fields on the tail were stimulated, produced AP of 60-100 mV amplitude (Walters et al., 2004).

Three pre-treatment (-PMA or -dbcAMP) tests were recorded with a $5 \mathrm{~min}$ interval between tests, and the baseline response 
illustrated in the figures was calculated from their average. Posttreatment test responses were then evoked at 5, 15, and 30 min after PMA or dbcAMP application for $10 \mathrm{~min}$ from the perfusion pipette. To measure excitability in tail PVC SNs, a protocol was modified from previous experiments (Fieber et al., 2010; Kempsell and Fieber, 2014). Depolarizing current was applied to SN in increasing increments of $0.1 \mathrm{nA}$ for $500 \mathrm{~ms}$ until the $\mathrm{SN}$ fired a single AP, then the single AP evoked by this depolarization was confirmed 3 times (baseline response; 5 min interval between tests). PMA (50 nM) or dbcAMP $(20 \mu \mathrm{M})$ was perfused onto the pleural-pedal ganglion for 10 min at concentrations known to induce forms of modulation including synaptic facilitation, increased AP duration and increased excitability in tail SNs (Carlson and Fieber, 2011; Carlson et al., 2012). After treatments of either PMA or dbcAMP, the same depolarizing current used to establish the baseline was applied, and the number of AP produced in the SN was counted.

Glass capillary microelectrodes of 5-15 $\mathrm{M} \Omega$ resistance were used for intracellular recordings in tail SN. All recordings were made at room temperature of $\sim 23^{\circ} \mathrm{C}$ using pClamp10 software with BRAMP-01R and ELC-01MX amplifiers (ALA Scientific Instruments, Farmingdale, NY, USA) connected to a PC and Digidata 1440 A A/D converter.

\section{Solutions}

Extracellular solution consisted of ASW containing (mM) 417 $\mathrm{NaCl}, 10 \mathrm{KCl}, 10 \mathrm{CaCl}_{2}, 55 \mathrm{MgCl}_{2}$, and $15 \mathrm{HEPES}-\mathrm{NaOH}, \mathrm{pH}$ 7.6. The pipette solution for intracellular recordings in intact ganglia consisted of $3 \mathrm{M} \mathrm{KCl}$. Intracellular solution for wholecell voltage clamp recordings consisted of (mM) $458 \mathrm{KCl}, 2.9$ $\mathrm{CaCl}_{2}\left(2 \mathrm{H}_{2} \mathrm{O}\right), 2.5 \mathrm{MgCl}_{2} \cdot\left(6 \mathrm{H}_{2} \mathrm{O}\right), 5 \mathrm{Na}_{2} \mathrm{ATP}, 1$ EGTA, and 40 HEPES-KOH, pH 7.4. Solutions containing L-Glu, 5-HT-HCl, PMA, or dbcAMP sodium salt in ASW were prepared daily from $0.5 \mathrm{M}$ stocks as previously reported (Carlson et al., 2012). All reagents were from Sigma-Aldrich (St. Louis, MO, USA).

\section{Data Acquisition and Analysis}

Data were expressed as mean \pm SE. Significant differences, such as that occurring during 5-HT treatment, were determined by one-way within subjects (repeated-measures) ANOVA. After the ANOVA, individual differences were compared against baseline using Tukey's post hoc test. All analyses were performed using the open source R statistical program (Vienna, Austria). Differences at $p \leq 0.05$ were accepted as significant.

\section{Results}

Sexual maturity occurred by age 7 months and median lifespans were 362 and 369 days for the two cohorts studied. Morphological and aging characteristics in aging Aplysia were reported in a previous study (Kempsell and Fieber, 2014).

\section{5-HT Facilitated Mature but not Aged II Tail SN Response to L-Glu}

A $100 \mathrm{~ms}$ pulse of L-Glu (1 mM) evoked excitatory currents in $\mathrm{SN}$ from mature Aplysia and in $\mathrm{SN}$ from their aged
II siblings (Figure 1A), although L-Glu current density was significantly smaller in aged II SN (mature: $2.5 \pm 0.6 \mathrm{pA} / \mathrm{pF}$, aged II: $1.3 \pm 0.2 \mathrm{pA} / \mathrm{pF} ; p \leq 0.05,2$-sample $t$-test), consistent with previously reported findings (Fieber et al., 2010). 5-HT treatment significantly potentiated L-Glu current density at all time points after treatment was initiated in mature $\mathrm{SN}$ but not in SN from aged II sibling animals (Figure 1B; $p \leq 0.05$, repeated measures ANOVA; mature $n=16$ aged II $n=20)$. Facilitation of mature SN L-Glu evoked responses were maintained even following $10 \mathrm{~min}$ ASW washout $(p \leq 0.05$ for 7-20 min time points compared to baseline; Tukey's post hoc tests). In SN isolated from aged II animals, 5-HT treatment did not change L-Glu current density. Thus, 5-HT-induced facilitation of L-Glu-evoked responses was absent in aged II SN.

\section{Activators of PKA and PKC Rescued Facilitation of L-Glu Currents in Isolated Aged II SN}

5-HT-induced facilitation in tail $\mathrm{SN}$ and $\mathrm{MN}$ is dependent on second messenger cascades including PKA- and PKC-mediated signaling (Kandel, 2001; Glanzman, 2008). The aging failure in 5HT-induced facilitation led us to hypothesize that either deficient 5-HT receptors or altered G-protein-dependent cascades might be responsible. We and others previously demonstrated that PMA facilitated L-Glu currents in Aplysia SN (Carlson and Fieber, 2012) and MN (Braha et al., 1990; Villareal et al., 2009). Furthermore, cAMP was previously shown to increase tail SN excitability and facilitate tail SN-MN transmission (Brunelli et al., 1976; Baxter and Byrne, 1990).

To test if the intracellular second messenger systems were intact or could be salvaged, we treated aged II SN with chemical analogs of second messengers downstream of G-protein initiated signaling. PMA treatment significantly increased L-Glu current density in aged II SNs (Figures 2A,B; $p \leq 0.05$, repeated measures ANOVA; $n=7$ ) to nearly the same extent as 5-HT modulated mature SN (Figure 1B), and L-Glu-evoked currents remained augmented following washout ( $p \leq 0.05$ for $5-16$ min time points compared to baseline; Tukey's post hoc tests). dbcAMP similarly enhanced L-Glu currents in cultured aged II SN (Figures 2A,B; $p \leq 0.05$, repeated measures ANOVA; $n=8$ ), with facilitation of L-Glu currents persisting following $10 \mathrm{~min}$ washout with ASW ( $p \leq 0.05$ for all time points after 8 min dbcAMP compared to baseline; Tukey's post hoc tests). Whereas PMA in aged II SN resulted in $90.1 \%$ of the L-Glu-induced current facilitation caused by $5-\mathrm{HT}$ treatment in mature $\mathrm{SN}, 10 \mathrm{~min}$ dbcAMP treatment achieved $82.3 \%$ of mature SN 5-HT-induced facilitation. Thus, activators of the PKC and PKA second messenger signaling cascades in aged II SN caused facilitation of the L-Glu currents similar to 5-HT-induced facilitation in mature $\mathrm{SN}$.

\section{Activators of PKA and PKC Rescued Aged Tail SN Function in a Semi Intact Preparation}

PMA and dbcAMP previously were shown to increase tail SN excitability and facilitate tail SN-MN transmission (Byrne et al., 1988; Kandel, 2001). We recently reported that synaptic 
A

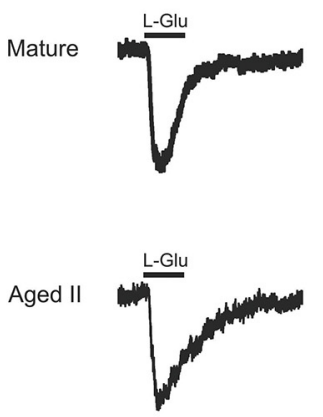

$10 \min 5-\mathrm{HT}$
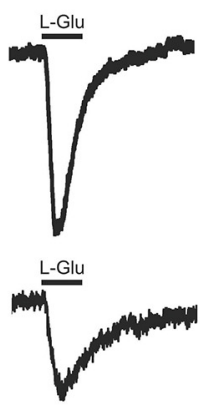

10 min washout
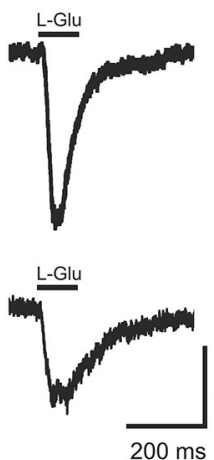

B $200 \mathrm{pA}$

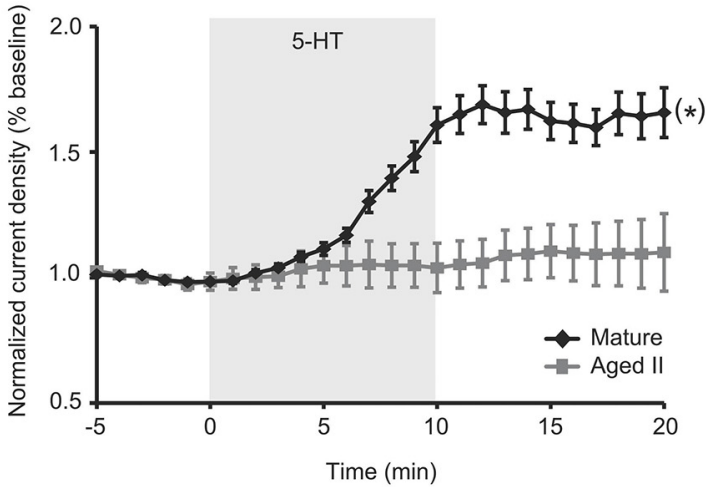

FIGURE 1 | 5-HT-induced facilitation of L-glutamate (L-Glu) currents was present in mature tail sensory neurons (SN), but absent in aged II tail SN. (A) Representative currents evoked in response to $100 \mathrm{~ms}$ pulse of L-Glu in isolated SN before 5-HT, after 10 min 5-HT, and after 10 min washout of 5-HT. (B) While current density increased significantly following $5-\mathrm{HT}$ treatment in isolated SN from mature animals, no change was observed in aged II SN. $\left({ }^{*}\right)$ denotes significant overall increase in current density at $p \leq 0.05$ via repeated measures ANOVA ( $n=16$ for mature, $n=20$ for aged II). Post hoc comparisons responsible for this difference are summarized in results.

A

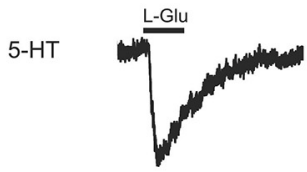

PMA

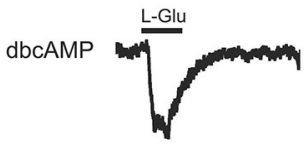

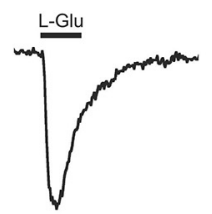

10 min treatment
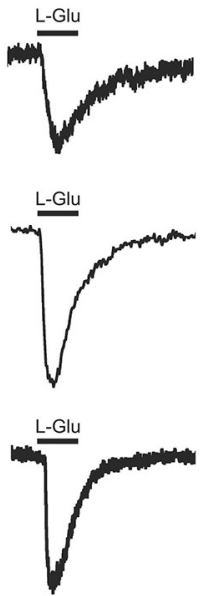
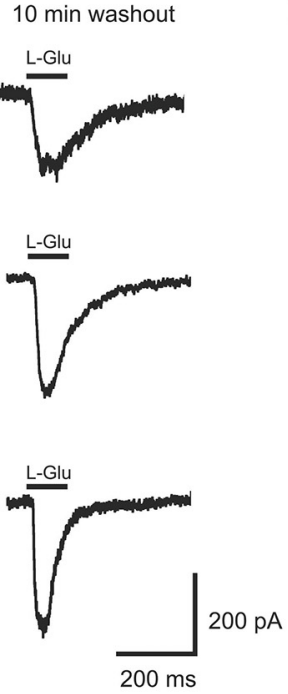

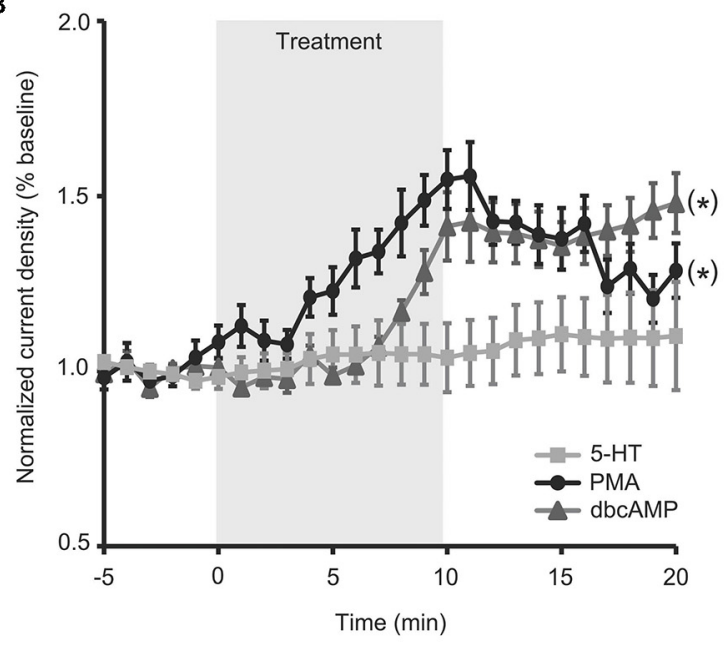

FIGURE 2 | Activators of protein kinase A (PKA) and protein kinase C (PKC) signaling rescued facilitation of L-Glu currents in isolated aged II SN. (A) Representative L-Glu currents in response to perfusion of isolated aged II SN with PMA or dbcAMP, with the 5-HT-modulated L-Glu currents in aged II tail SN reproduced from Figure 1A. (B) L-Glu current density increased significantly following PMA $(n=7)$ and dbcAMP $(n=8)$ treatment in aged II SN; the ineffective 5-HT treatment time course is reproduced from Figure 1B. $\left({ }^{*}\right)$ denotes significant overall increase in current density at $p \leq 0.05$ via repeated measures ANOVA. Post hoc comparisons responsible for these differences are summarized in results.

facilitation declined during aging in the TWR circuit whether the sensitizing stimulus was electrical stimulation or 5-HT treatment (Kempsell and Fieber, 2015). The ability of isolated aged II SN to respond to PMA and dbcAMP with facilitiated L-Glu-induced currents implied that excitability modulating intracellular pathways were at least partially intact in aging, and prompted questions about whether these agents could restore TWR responses to sensitizing stimuli that were absent in aged animals. We tested PMA and dbcAMP on SN excitability in ganglia-tail preparations from mature and aged II sibling Aplysia.
The PMA results are shown in Figures 3A,B. Depolarizing current of $0.3-1.5 \mathrm{nA}$ induced a single AP in control conditions in mature and aged II SN. The same depolarizing pulse that produced a single AP in baseline conditions evoked a significantly greater number of AP when tested after PMA treatment in both mature (Figures 3A,B, $p \leq 0.01$ at 5, 15, and 30 min compared to baseline, Tukey's post hoc analysis; $n=12)$ and aged II tail SN ( $p \leq 0.05$ at 5,15 , and $30 \mathrm{~min}$ compared to baseline, Tukey's post hoc analysis; $n=11$ ). dbcAMP results are shown in additional mature and aged II preparations 
in Figures 3C,D. The same depolarizing pulse that produced a single AP in baseline conditions evoked a significantly greater number of AP when tested after dbcAMP treatment in both mature (Figures 3C,D, $p \leq 0.01$ at 5 and $15 \mathrm{~min}, p \leq 0.05$ at 30 min compared to baseline, Tukey's post hoc analysis; $n=13$ ) and aged II tail SN ( $p \leq 0.05$ at 5 and 15 min compared to baseline, Tukey's post hoc analysis; $n=12$ ). Note that the dbcAMP-induced excitability increase in aged II ganglia that persisted for $15 \mathrm{~min}$ post-treatment returned to baseline after $30 \mathrm{~min}$. Thus, activators of PKA and PKC signaling rescued aged II tail SN function, at least temporarily.

\section{Discussion}

5-HT released at synapses during sensitization in Aplysia increases SN excitability and SN-MN transmission in tail- and gill-withdrawal reflexes via PKA- and PKC-induced signaling in both SN and MN (Brunelli et al., 1976; Walters et al., 1983b; Glanzman et al., 1989; Mackey et al., 1989; Mercer et al., 1991; Levenson et al., 1999; Marinesco and Carew, 2002; Philips et al., 2011). These elemental processes define the role of 5-HT in stimulating the formation and maintenance of memory. We have recently described changes in shortterm memory for sensitization in TWR and related declines in facilitation between tail SN-MN synapses during aging, suggesting that nonassociative learning is impaired in aged Aplysia (Kempsell and Fieber, 2015). In that study, 5HT-exposed, mature SN in intact ganglia responded to depolarizing stimuli with multiple AP compared to the single AP response before 5-HT, whereas aged $\mathrm{SN}$ showed no change in excitability with 5-HT. In a separate readout of SN excitability, we found here that 5-HT potentiated L-Gluinduced excitatory currents of mature but not aged isolated tail SN.

The result that 5 -HT was ineffective at inducing synaptic facilitation in aged neurons suggests that the 5-HT

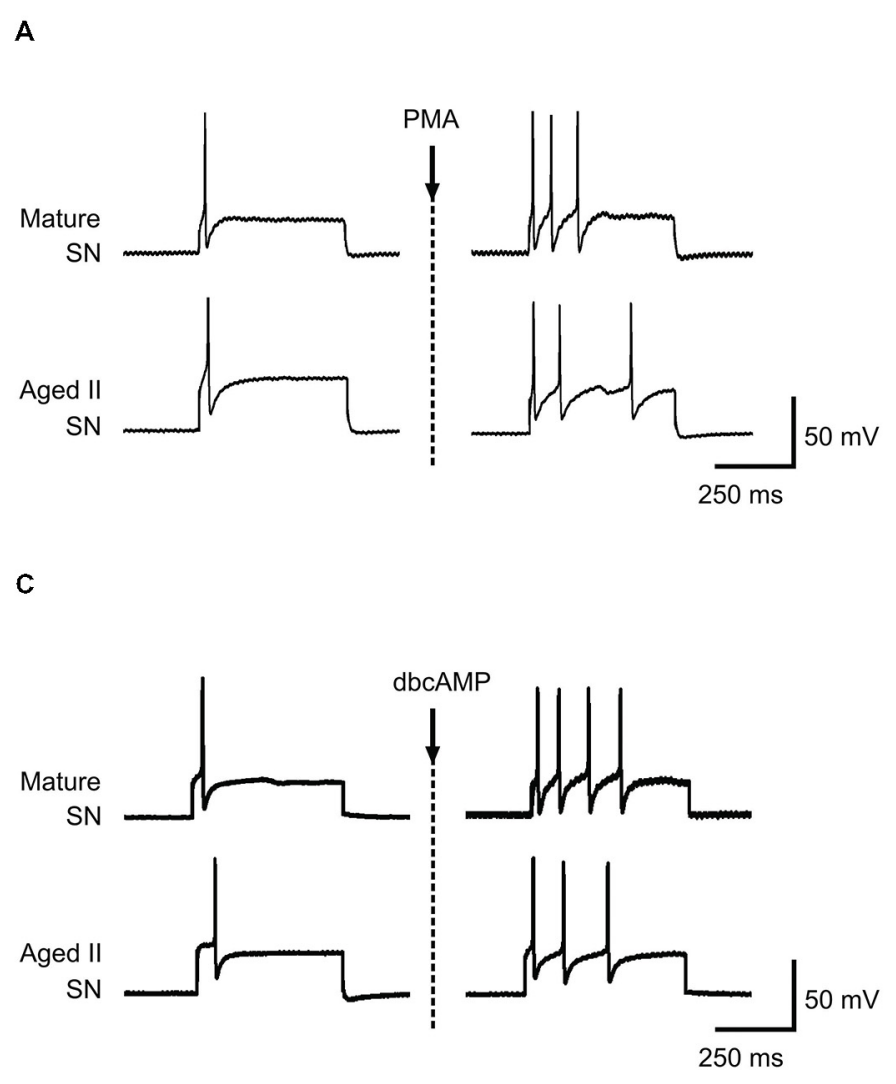

B

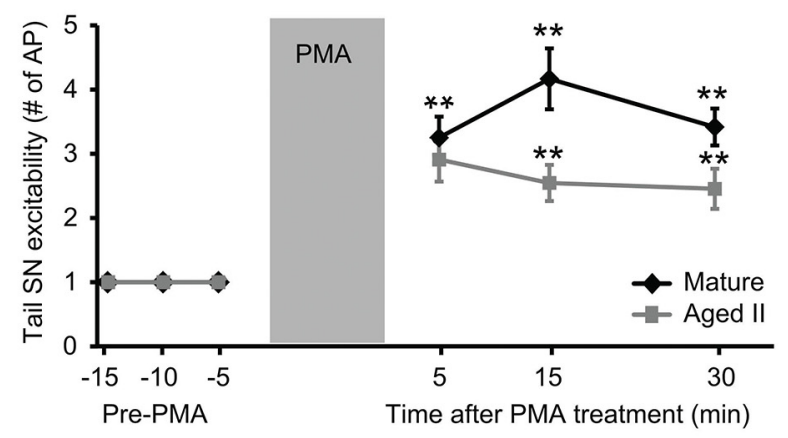

D

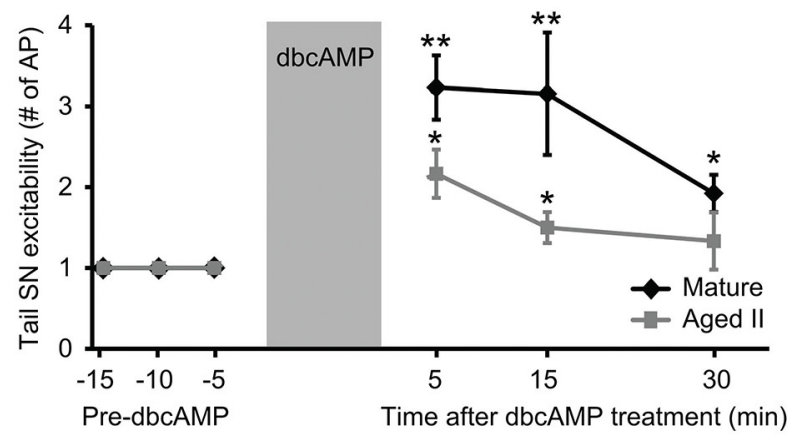

FIGURE 3 | Treatment with activators of PKA and PKC signaling rescued aged II SN performance in semi intact preparation. (A) Representative responses in mature and aged II tail SN during depolarizing current injection before and 5 min after the end of 10 min PMA perfusion (50 nM) onto the pleural-pedal ganglion. Mature and aged II neurons were maintained at a holding potential of $-43 \mathrm{mV}$ during the experiment. (B) In both mature $(n=12)$ and aged II $(n=11)$ tail $\mathrm{SN}$, the number of AP in response to depolarizing current injection was significantly increased at 5, 15, and 30 min following the end of PMA treatment. $(* *)$ denotes significant increase compared to baseline at $p \leq 0.01$, Tukey's post hoc tests. (C) Responses in mature and aged II tail SN before and 5 min after dbcAMP perfusion $(20 \mu \mathrm{M})$. Mature and aged II neurons were maintained at a holding potential of $-43 \mathrm{mV}$ during the experiment. (D) In both mature $(n=13)$ and aged II $(n=12)$ tail $\mathrm{SN}$, the number of AP in response to depolarizing current injection was significantly increased at 5 and 15 min following dbcAMP treatment. At 30 min after the end of dbcAMP application, excitability of mature SN was still enhanced, while aged II SN excitability had returned to baseline value. $\left({ }^{*}\right)$ and $\left({ }^{* *}\right)$ denotes significant increase compared to baseline at $p \leq 0.05$ and $p \leq 0.01$, respectively, Tukey's post hoc tests. 
receptor-initiated signaling cascade that increases cAMP, and results in sensitization, is compromised during aging. The compromise is somewhere upstream of cAMP, thereby almost eliminating sensitization in aged SN. An analog of cAMP that activates PKA and an analog of diacylglycerol that activates PKC imitated the effects of 5-HT on mature SN by potentiating L-Glu currents of isolated aged SN. These agents also increased the excitability of aged intact tail SN to depolarizing stimuli. Although bath application of PMA or dbcAMP most likely activated many neurons, including interneurons, the end result was enhanced tail SN excitability, even in ganglia from aged II animals. Thus stimulation of the intracellular second messenger cascade critical to learningrelated facilitation in Aplysia mitigated aging SN performance declines.

While facilitation of excitation occurs via activation of intracellular signaling pathways, membrane 5-HT receptors and associated G-proteins activate these signaling cascades. Our results suggest two things about aging of facilitation in TWR. First, the second messenger cascade of specifically the SN failed in aging. Aging defects also may be present in other components of the tail withdrawal circuit, but the observation that L-Glu current potentiation of isolated aged $\mathrm{SN}$ by 5 -HT was impaired demonstrated that the aged $\mathrm{SN}$ had an unmistakable defect. Second, if activators of PKA or PKC signaling were applied, permitting the intracellular second messenger cascade to proceed past the point of phosphorylation of a kinase, facilitation was observed in aged SN. L-Glu current potentiation of aged $\mathrm{SN}$ by activators of PKA or PKC approximated that induced by $5-\mathrm{HT}$ in mature $\mathrm{SN}$. The number of AP produced in response to depolarizations was restored to values approximating the facilitory effects on mature SN by activators of PKA or PKC. This suggests that a primary aging defect in facilitation of SN excitability is loss of a component upstream of PKA- and PKC-dependent signaling. It also suggests that correction at the point of what is presumed to be kinase phosphorylation is necessary to recover facilitation.

G-protein coupled signaling is altered in many animal models of aging (Stern et al., 1985; Bickford et al., 1986; Bickford-Wimer et al., 1988; Shen and Barnes, 1996; Ayyagari et al., 1998; Foster, 1999; Nicolle et al., 1999). We observed that the facilitation impairment in aged SN was repaired by components of either PKA or PKC dependent signaling. The defect may be altered $\mathrm{G}_{s}$-5-HT-receptor coupling, or reduced activation of adenylyl cyclase, leading to inadequate levels of cAMP and decreased PKA activation. The restorative effects of PMA suggested that aging in $\mathrm{SN}$ affects multiple second messenger signaling cascades. The PKA and PKC kinase pathways regulate several neuronal processes involving ion channels, neurotransmitter receptors, $\mathrm{Ca}^{2+}$ dynamics, and synaptic plasticity. Signaling components downstream of PKA and PKC may remain intact in aged tail SN.

Stimulation of second messenger signaling has been shown to reverse memory loss and physiological defects in the aging hippocampus (Bach et al., 1999). Furthermore, 5-HT receptor activation, specifically $5-\mathrm{HT}_{4}$ and $5-\mathrm{HT}_{7}$ receptors and the
$\mathrm{G}_{\mathrm{s}}$ cascade, was shown to restore age-related memory deficits in aged animals (Moser et al., 2002). Our findings support the hypothesis that deficient 5-HT receptor physiology and second messenger-dependent signaling results in age-related learning impairments and altered neuronal functioning in Aplysia.

Decreased synaptic strength during aging is the result of declines in postsynaptic responsiveness including decreases in level of expression of ionotrophic glutamate receptors (iGluR; Magnusson et al., 2002). Studies have shown a decrease in L-Glumediated excitatory transmission during aging corresponding to changes in the composition of subunits of major iGluR including alpha-amino-3-hydroxy-5-methylisoxazole-4-propionic acid receptors (AMPAR) and N-methyl-D-aspartate receptors (NMDAR; Barnes et al., 1992, 1997; Jouvenceau et al., 1998; Magnusson, 1998; Magnusson et al., 2000; Potier et al., 2000; Brim et al., 2013). Specifically, age-related declines in NMDAR binding density and expression of NMDAR subunits in the frontal lobe and hippocampus of rodents were associated with declines in spatial memory during aging (Magnusson et al., 2007; Zhao et al., 2009). The consequences of these changes in iGluR function during aging are decreased synaptic strength resulting in changes in cellular analogs of learning and memory including reduced induction and maintenance of long-term potentiation and lower thresholds for long-term depression (Foster, 1999; Eckles-Smith et al., 2000; Billard and Rouaud, 2007; Bodhinathan et al., 2010; Kumar and Foster, 2013; Lee et al., 2014; Guidi et al., 2015). Age-related changes in synaptic plasticity resulted in learning failure and memory loss including poor performance in spatial memory tasks (Barnes et al., 2000; Almaguer et al., 2002).

Tail SN use L-Glu as their primary excitatory neurotransmitter (Dale and Kandel, 1993; Fox and Lloyd, 1999; Levenson et al., 2000a,b; Ha et al., 2006), and the excitatory responses to L-Glu have been described (Carlson and Fieber, 2011; Carlson et al., 2012), including L-Glu-induced current amplitude declines in old tail SN (Fieber et al., 2010; Kempsell and Fieber, 2014). The latter studies suggested that losses in SN excitability are a hallmark of aging.

Although the physiological role of the L-Glu excitatory responses in tail $\mathrm{SN}$ is not established, the synapses of these neurons are vulnerable to synaptic facilitation and depression (Walters et al., 1983b; Stopfer and Carew, 1996), thus excitatory agonists including L-Glu may serve as neuromodulators. Subtypes of the AMPA and NMDA types of glutamate receptors as well as glutamate-mediated excitatory transmission has been shown to decrease during brain aging (Barnes et al., 1992; Jouvenceau et al., 1998; Potier et al., 2000; Clayton and Browning, 2001; Newcomer and Krystal, 2001; Barria and Malinow, 2002; Clayton et al., 2002; Magnusson et al., 2002). AMPA and NMDA receptors contribute to the induction and expression, respectively, of long-term synaptic plasticity, and age-related loss of functional receptors results in impaired synaptic plasticity and learning deficits (Adams et al., 2001; Clayton et al., 2002). As it has been previously shown that L-Glu activates NMDAlike receptors in Aplysia SN (Carlson and Fieber, 2011), it is possible that the decrements in iGluR signaling described in this study are due to NMDAR dysfunction similar to that seen in 
mammalian models of aging (Foster et al., 2001). Altered iGluR composition in aged Aplysia neurons likely contributes to the changes in learning and related changes in proxies for synaptic plasticity found in this study and others (Kempsell and Fieber, 2015).

\section{Conclusion}

Neuronal proxies for synaptic plasticity including 5-HT-induced excitability and facilitation of L-Glu currents in tail SN were impaired during aging. Treatment with activators of second messenger signaling cascades rescued facilitation of L-Gluevoked responses and increased excitability in aged tail SN,

\section{References}

Adams, M. M., Smith, T. D., Moga, D., Gallagher, M., Wang, Y., Wolfe, B. B., et al. (2001). Hippocampal dependent learning ability correlates with N-methyl-Daspartate (NMDA) receptor levels in CA3 neurons of young and aged rats. J. Comp. Neurol. 432, 230-243. doi: 10.1002/cne.1099

Almaguer, W., Estupiñán, B., Uwe Frey, J., and Bergado, J. A. (2002). Aging impairs amygdala-hippocampus interactions involved in hippocampal LTP. Neurobiol. Aging 23, 319-324. doi: 10.1016/s0197-4580(01)00278-0

Ayyagari, P. V., Gerber, M., Joseph, J. A., and Crews, F. T. (1998). Uncoupling of muscarinic cholinergic phosphoinositide signals in senescent cerebral cortical and hippocampal membranes. Neurochem. Int. 32, 107-115. doi: 10. 1016/s0197-0186(97)00044-2

Bach, M. E., Barad, M., Son, H., Zhuo, M., Lu, Y. F., Shih, R., et al. (1999). Agerelated defects in spatial memory are correlated with defects in the late phase of hippocampal long-term potentiation in vitro and are attenuated by drugs that enhance the cAMP signaling pathway. Proc. Natl. Acad. Sci. U S A 96, 5280-5285. doi: 10.1073/pnas.96.9.5280

Barnes, C. A., Rao, G., Foster, T. C., and McNaughton, B. L. (1992). Regionspecific age effects on AMPA sensitivity: electrophysiological evidence for loss of synaptic contacts in hippocampal field CA1. Hippocampus 2, 457-468. doi: 10.1002/hipo.450020413

Barnes, C. A., Rao, G., and Houston, F. P. (2000). LTP induction threshold change in old rats at the perforant path-granule cell synapse. Neurobiol. Aging 21, 613-620. doi: 10.1016/s0197-4580(00)00163-9

Barnes, C. A., Rao, G., and Shen, J. (1997). Age-related decrease in the N-methylD-aspartateR-mediated excitatory postsynaptic potential in hippocampal region CA1. Neurobiol. Aging 18, 445-452. doi: 10.1016/s0197-4580(97) 00044-4

Barria, A., and Malinow, R. (2002). Subunit-specific NMDA receptor trafficking to synapses. Neuron 35, 345-353. doi: 10.1016/s0896-6273(02)00776-6

Baxter, D. A., and Byrne, J. H. (1990). Differential effects of cAMP and serotonin on membrane current, action-potential duration and excitability in somata of pleural sensory neurons of Aplysia. J. Neurophysiol. 64, 978-990.

Bickford, P. C., Hoffer, B. J., and Freedman, R. (1986). Diminished interaction of norepinephrine with climbing fiber inputs to cerebellar Purkinje neurons in aged Fischer 344 rats. Brain Res. 385, 405-410. doi: 10.1016/00068993(86)91092-9

Bickford-Wimer, P. C., Miller, J. A., Freedman, R., and Rose, G. M. (1988). Agerelated reduction in responses of rat hippocampal neurons to locally applied monoamines. Neurobiol. Aging 9, 173-179. doi: 10.1016/s0197-4580(88) $80047-2$

Billard, J. M., and Rouaud, E. (2007). Deficit of NMDA receptor activation in CA1 hippocampal area of aged rats is rescued by D-cycloserine. Eur. J. Neurosci. 25, 2260-2268. doi: 10.1111/j.1460-9568.2007.05488.x

Bodhinathan, K., Kumar, A., and Foster, T. C. (2010). Intracellular redox state alters NMDA receptor response during aging through $\mathrm{Ca} 2+$ /calmodulindependent protein kinase II. J. Neurosci. 30, 1914-1924. doi: 10.1523/jneurosci. 5485-09.2010 suggesting possible molecular targets with the potential to restore age-related memory impairment in Aplysia.

\section{Grants}

This work was funded by National Institutes of Health Grant P40 OD010952, and Maytag and Korein Foundation fellowships to ATK.

\section{Acknowledgments}

We gratefully acknowledge assistance from the staff of the University of Miami Aplysia Resource.

Braha, O., Dale, N., Hochner, B., Klein, M., Abrams, T. W., and Kandel, E. R. (1990). Second messengers involved in the two processes of presynaptic facilitation that contribute to sensitization and dishabituation in Aplysia sensory neurons. Proc. Natl. Acad. Sci. U S A 87, 2040-2044. doi: 10.1073/pnas. 87.5.2040

Brim, B. L., Haskell, R., Awedikian, R., Ellinwood, N. M., Jin, L., Kumar, A., et al. (2013). Memory in aged mice is rescued by enhanced expression of the GluN2B subunit of the NMDA receptor. Behav. Brain Res. 238, 211-226. doi: 10.1016/j. bbr.2012.10.026

Brunelli, M., Castellucci, V., and Kandel, E. R. (1976). Synaptic facilitation and behavioral sensitization in Aplysia: possible role of serotonin and cyclic AMP. Science 194, 1178-1181. doi: 10.1126/science. 186870

Byrne, J. H., Eskin, A., and Scholz, K. P. (1988). Neuronal mechanisms contributing to long-term sensitization in Aplysia. J. Physiol. (Paris) 83, $141-147$.

Carlson, S. L., and Fieber, L. A. (2011). Physiological evidence that D-aspartate activates a current distinct from ionotropic glutamate receptor currents in Aplysia californica neurons. J. Neurophysiol. 106, 1629-1636. doi: 10.1152/jn. 00403.2011

Carlson, S. L., and Fieber, L. A. (2012). Unique ionotropic receptors for Daspartate are a target for serotonin-induced synaptic plasticity in Aplysia californica. Comp. Biochem. Physiol. C Toxicol. Pharmacol. 155, 151-159. doi: 10.1016/j.cbpc.2011.04.001

Carlson, S. L., Kempsell, A. T., and Fieber, L. A. (2012). Pharmacological evidence that $\mathrm{D}$-aspartate activates a current distinct from ionotropic glutamate receptor currents in Aplysia californica. Brain Behav. 2, 391-401. doi: 10.1002/ brb3.60

Clayton, D. A., and Browning, M. D. (2001). Deficits in the expression of the NR2B subunit in the hippocampus of aged Fisher 344 rats. Neurobiol. Aging 22, 165-168. doi: 10.1016/s0197-4580(00)00196-2

Clayton, D. A., Mesches, M. H., Alvarez, E., Bickford, P. C., and Browning, M. D. (2002). A hippocampal NR2B deficit can mimic age-related changes in longterm potentiation and spatial learning in the Fischer 344 rat. J. Neurosci. 22, 3628-3637.

Dale, N., and Kandel, E. R. (1993). L-glutamate may be the fast excitatory transmitter of Aplysia sensory neurons. Proc. Natl. Acad. Sci. U S A 90, 7163-7167. doi: 10.1073/pnas.90.15.7163

Eckles-Smith, K., Clayton, D., Bickford, P., and Browning, M. D. (2000). Caloric restriction prevents age-related deficits in LTP and in NMDA receptor expression. Brain Res. Mol. Brain Res. 78, 154-162. doi: 10.1016/s0169$328 \mathrm{x}(00) 00088-7$

Fieber, L. A. (2000). The development of excitatory capability in Aplysia californica bag cells observed in cohorts. Brain Res. Dev. Brain Res. 122, 47-58. doi: 10. 1016/s0165-3806(00)00053-5

Fieber, L. A., Carlson, S. L., Capo, T. R., and Schmale, M. C. (2010). Changes in $\mathrm{D}$-aspartate ion currents in the Aplysia nervous system with aging. Brain Res. 1343, 28-36. doi: 10.1016/j.brainres.2010.05.001

Fieber, L. A., Carlson, S. L., Kempsell, A. T., Greer, J. B., and Schmale, M. C. (2013). Isolation of sensory neurons of Aplysia californica for patch clamp recordings of glutamatergic currents. J. Vis. Exp. 10:e50543. doi: 10.3791/50543 
Foster, T. C. (1999). Involvement of hippocampal synaptic plasticity in age-related memory decline. Brain Res. Brain Res. Rev. 30, 236-249. doi: 10.1016/s01650173(99)00017-x

Foster, T. C., Sharrow, K. M., Masse, J. R., Norris, C. M., and Kumar, A. (2001). Calcineurin links Ca2+ dysregulation with brain aging. J. Neurosci. 21, 4066-4073.

Fox, L. E., and Lloyd, P. E. (1999). Glutamate is a fast excitatory transmitter at some buccal neuromuscular synapses in Aplysia. J. Neurophysiol. 82, 1477-1488.

Gerdes, R., and Fieber, L. A. (2006). Life history and aging of captive-reared California sea hares (Aplysia californica). J. Am. Assoc. Lab. Anim. Sci. 45, $40-47$.

Glanzman, D. L. (2008). New tricks for an old slug: the critical role of postsynaptic mechanisms in learning and memory in Aplysia. Prog. Brain Res. 169, 277-292. doi: 10.1016/s0079-6123(07)00017-9

Glanzman, D. L. (2009). Habituation in Aplysia: the Cheshire cat of neurobiology. Neurobiol. Learn. Mem. 92, 147-154. doi: 10.1016/j.nlm.2009.03.005

Glanzman, D. L., Mackey, S. L., Hawkins, R. D., Dyke, A. M., Lloyd, P. E., and Kandel, E. R. (1989). Depletion of serotonin in the nervous system of Aplysia reduces the behavioral enhancement of gill withdrawal as well as the heterosynaptic facilitation produced by tail shock. J. Neurosci. 9, 42004213.

Guidi, M., Kumar, A., and Foster, T. C. (2015). Impaired attention and synaptic senescence of the prefrontal cortex involves redox regulation of NMDA receptors. J. Neurosci. 35, 3966-3977. doi: 10.1523/jneurosci.3523-14.2015

Ha, T. J., Kohn, A. B., Bobkova, Y. V., and Moroz, L. L. (2006). Molecular characterization of NMDA-like receptors in Aplysia and Lymnaea: relevance to memory mechanisms. Biol. Bull. 210, 255-270. doi: 10.2307/4134562

Jouvenceau, A., Dutar, P., and Billard, J. M. (1998). Alteration of NMDA receptormediated synaptic responses in CA1 area of the aged rat hippocampus: contribution of GABAergic and cholinergic deficits. Hippocampus 8, 627-637. doi: 10.1002/(sici)1098-1063(1998)8:6<627::aid-hipo5>3.0.co;2-x

Kandel, E. R. (2001). The molecular biology of memory storage: a dialogue between genes and synapses. Science 294, 1030-1038. doi: 10.1126/science. 1067020

Kempsell, A. T., and Fieber, L. A. (2014). Behavioral aging is associated with reduced sensory neuron excitability in Aplysia californica. Front. Aging Neurosci. 6:84. doi: 10.3389/fnagi.2014.00084

Kempsell, A. T., and Fieber, L. A. (2015). Aging in sensory and motor neurons results in learning failure in Aplysia californica. PLoS One 10:e0127056. doi: 10. 1371/journal.pone. 0127056

Kumar, A., and Foster, T. C. (2007). "Neurophysiology of old neurons and synapses," in Brain Aging: Models, Methods and Mechanisms, ed. D. R. Riddle (Boca Raton, FL: CRC Press), 229-241.

Kumar, A., and Foster, T. C. (2013). Linking redox regulation of NMDAR synaptic function to cognitive decline during aging. J. Neurosci. 33, 15710-15715. doi: 10.1523/JNEUROSCI.2176-13.2013

Kumar, A., Rani, A., Tchigranova, O., Lee, W. H., and Foster, T. C. (2012). Influence of late-life exposure to environmental enrichment or exercise on hippocampal function and CA1 senescent physiology. Neurobiol. Aging 33, 828.e1-828.e17. doi: 10.1016/j.neurobiolaging.2011.06.023

Lee, W. H., Kumar, A., Rani, A., and Foster, T. C. (2014). Role of antioxidant enzymes in redox regulation of N-methyl-D-aspartate receptor function and memory in middle-aged rats. Neurobiol. Aging 35, 1459-1468. doi: 10.1016/j. neurobiolaging.2013.12.002

Levenson, J., Byrne, J. H., and Eskin, A. (1999). Levels of serotonin in the hemolymph of Aplysia are modulated by light/dark cycles and sensitization training. J. Neurosci. 19, 8094-8103.

Levenson, J., Endo, S., Kategaya, L. S., Fernandez, R. I., Brabham, D. G., Chin, J., et al. (2000a). Long-term regulation of neuronal high-affinity glutamate and glutamine uptake in Aplysia. Proc. Natl. Acad. Sci. U S A 97, 12858-12863. doi: 10.1073/pnas.220256497

Levenson, J., Sherry, D. M., Dryer, L., Chin, J., Byrne, J. H., and Eskin, A. (2000b). Localization of glutamate and glutamate transporters in the sensory neurons of Aplysia. J. Comp. Neurol. 423, 121-131. doi: 10.1002/10969861(20000717)423:1<121::aid-cne10>3.0.co;2-e

Mackey, S. L., Kandel, E. R., and Hawkins, R. D. (1989). Identified serotonergic neurons LCB1 and RCB1 in the cerebral ganglia of Aplysia produce presynaptic facilitation of siphon sensory neurons. J. Neurosci. 9, 4227-4235.
Magnusson, K. R. (1998). Aging of glutamate receptors: correlations between binding and spatial memory performance in mice. Mech. Ageing Dev. 104, 227-248. doi: 10.1016/s0047-6374(98)00076-1

Magnusson, K. R., Nelson, S. E., and Young, A. B. (2002). Age-related changes in the protein expression of subunits of the NMDA receptor. Brain Res. Mol. Brain Res. 99, 40-45. doi: 10.1016/s0169-328x(01)00344-8

Magnusson, K. R., Scanga, C., Wagner, A. E., and Dunlop, C. (2000). Changes in anesthetic sensitivity and glutamate receptors in the aging canine brain. J. Gerontol. A Biol. Sci. Med. Sci. 55, B448-B454. doi: 10.1093/gerona/ 55.9.b448

Magnusson, K. R., Scruggs, B., Zhao, X., and Hammersmark, R. (2007). Agerelated declines in a two-day reference memory task are associated with changes in NMDA receptor subunits in mice. BMC Neurosci. 8:43. doi: 10.1186/14712202-8-43

Marinesco, S., and Carew, T. J. (2002). Serotonin release evoked by tail nerve stimulation in the CNS of aplysia: characterization and relationship to heterosynaptic plasticity. J. Neurosci. 22, 2299-2312.

Mercer, A. R., Emptage, N. J., and Carew, T. J. (1991). Pharmacological dissociation of modulatory effects of serotonin in Aplysia sensory neurons. Science 254, 1811-1813. doi: 10.1126/science.1662413

Moser, P. C., Bergis, O. E., Jegham, S., Lochead, A., Duconseille, E., Terranova, J. P., et al. (2002). SL65.0155, a novel 5-hydroxytryptamine(4) receptor partial agonist with potent cognition-enhancing properties. J. Pharmacol. Exp. Ther. 302, 731-741. doi: 10.1124/jpet.102.034249

Newcomer, J. W., and Krystal, J. H. (2001). NMDA receptor regulation of memory and behavior in humans. Hippocampus 11, 529-542. doi: 10.1002/hipo.1069

Nicolle, M. M., Colombo, P. J., Gallagher, M., and McKinney, M. (1999). Metabotropic glutamate receptor-mediated hippocampal phosphoinositide turnover is blunted in spatial learning-impaired aged rats. J. Neurosci. 19, 9604-9610.

Oh, M. M., McKay, B. M., Power, J. M., and Disterhoft, J. F. (2009). Learningrelated postburst afterhyperpolarization reduction in CA1 pyramidal neurons is mediated by protein kinase A. Proc. Natl. Acad. Sci. U S A 106, 1620-1625. doi: 10.1073/pnas.0807708106

Philips, G. T., Sherff, C. M., Menges, S. A., and Carew, T. J. (2011). The tail-elicited tail withdrawal reflex of Aplysia is mediated centrally at tail sensory-motor synapses and exhibits sensitization across multiple temporal domains. Learn. Mem. 18, 272-282. doi: 10.1101/lm.2125311

Potier, B., Poindessous-Jazat, F., Dutar, P., and Billard, J. M. (2000). NMDA receptor activation in the aged rat hippocampus. Exp. Gerontol. 35, 1185-1199. doi: 10.1016/s0531-5565(00)00122-4

Shen, J., and Barnes, C. A. (1996). Age-related decrease in cholinergic synaptic transmission in three hippocampal subfields. Neurobiol. Aging 17, 439-451. doi: 10.1016/0197-4580(96)00020-6

Stern, W. C., Pugh, W. W., and Morgane, P. J. (1985). Single unit activity in frontal cortex and caudate nucleus of young and old rats. Neurobiol. Aging 6, 245-248. doi: 10.1016/0197-4580(85)90058-2

Stopfer, M., and Carew, T. J. (1996). Heterosynaptic facilitation of tail sensory neuron synaptic transmission during habituation in tail-induced tail and siphon withdrawal reflexes of Aplysia. J. Neurosci. 16, 4933-4948.

Stopfer, M., Chen, X., Tai, Y. T., Huang, G. S., and Carew, T. J. (1996). Site specificity of short-term and long-term habituation in the tail-elicited siphon withdrawal reflex of Aplysia. J. Neurosci. 16, 4923-4932.

Sutton, M. A., Ide, J., Masters, S. E., and Carew, T. J. (2002). Interaction between amount and pattern of training in the induction of intermediate- and long-term memory for sensitization in aplysia. Learn. Mem. 9, 29-40. doi: 10.1101/lm. 44802

Van der Zee, E. A., Luiten, P. G., and Disterhoft, J. F. (1997). Learning-induced alterations in hippocampal PKC-immunoreactivity: a review and hypothesis of its functional significance. Prog. Neuropsychopharmacol. Biol. Psychiatry 21, 531-572. doi: 10.1016/s0278-5846(97)00017-1

Van der Zee, E. A., Palm, I. F., O'connor, M., Maizels, E. T., Hunzicker-Dunn, M., and Disterhoft, J. F. (2004). Aging-related alterations in the distribution of $\mathrm{Ca}^{2+}$-dependent PKC isoforms in rabbit hippocampus. Hippocampus 14, 849-860. doi: 10.1002/hipo.20000

Villareal, G., Li, Q., Cai, D., Fink, A. E., Lim, T., Bougie, J. K., et al. (2009). Role of protein kinase $\mathrm{C}$ in the induction and maintenance of serotonin-dependent enhancement of the glutamate response in isolated siphon motor neurons of 
Aplysia californica. J. Neurosci. 29, 5100-5107. doi: 10.1523/JNEUROSCI.414908.2009

Walters, E. T., Bodnarova, M., Billy, A. J., Dulin, M. F., Díaz-Ríos, M., Miller, M. W., et al. (2004). Somatotopic organization and functional properties of mechanosensory neurons expressing sensorin-A mRNA in Aplysia californica. J. Comp. Neurol. 471, 219-240. doi: 10.1002/cne.20042

Walters, E. T., Byrne, J. H., Carew, T. J., and Kandel, E. R. (1983a). Mechanoafferent neurons innervating tail of Aplysia. I. Response properties and synaptic connections. J. Neurophysiol. 50, 1522-1542.

Walters, E. T., Byrne, J. H., Carew, T. J., and Kandel, E. R. (1983b). Mechanoafferent neurons innervating tail of Aplysia. II. Modulation by sensitizing stimulation. J. Neurophysiol. 50, 1543-1559.

Zhao, X., Rosenke, R., Kronemann, D., Brim, B., Das, S. R., Dunah, A. W., et al. (2009). The effects of aging on N-methyl-D-aspartate receptor subunits in the synaptic membrane and relationships to long-term spatial memory. Neuroscience 162, 933-945. doi: 10.1016/j.neuroscience.2009. 05.018

Conflict of Interest Statement: The authors declare that the research was conducted in the absence of any commercial or financial relationships that could be construed as a potential conflict of interest.

Copyright $\odot 2015$ Kempsell and Fieber. This is an open-access article distributed under the terms of the Creative Commons Attribution License (CC BY). The use, distribution and reproduction in other forums is permitted, provided the original author(s) or licensor are credited and that the original publication in this journal is cited, in accordance with accepted academic practice. No use, distribution or reproduction is permitted which does not comply with these terms. 